\title{
The effect of life expectancy on schooling: Evidence from the international health transition
}

\author{
by
}

\section{Casper Worm Hansen}

Discussion Papers on Business and Economics

No. 6/2012

\author{
FURTHER INFORMATION \\ Department of Business and Economics \\ Faculty of Social Sciences \\ University of Southern Denmark \\ Campusvej 55 \\ DK-5230 Odense M \\ Denmark \\ Tel.: +4565503271 \\ Fax: +4565503237 \\ E-mail: lho@sam.sdu.dk \\ http://www.sdu.dk/ivoe
}

ISBN 978-87-91657-59-7 


\title{
The effect of life expectancy on schooling: Evidence from the international health transition
}

\author{
Casper Worm Hansen \\ University of Southern Denmark, Department of Business and Economics*
}

\begin{abstract}
The influence of life expectancy on schooling is usually thought of as one main mechanism by which life expectancy possibly affects income per capita and thus economic development. However, the relevance of this channel has been qualified in recent research. This paper studies whether life expectancy has an effect on the number of years of schooling. Using cross-country panel data, the empirical analysis finds that a 1 percent rise in life expectancy at birth increases years of schooling by 3.5 percent. The analysis also demonstrates that this result is not driven by child mortality or by general improvements in living standards. All in all, the evidence presented suggests that health, as measured by life expectancy, has a direct positive effect on the accumulation of human capital.
\end{abstract}

Key Words: Life expectancy, human capital, economic development.

JEL: I15, J24, O11.

\footnotetext{
*Address: Campusvej 55, 5230 Odense, Denmark; Email: cwh@sam.sdu.dk; Phone: +45 65503363.
} 


\section{Introduction}

What causes some countries in the world to remain underdeveloped, and what can we do to help those countries escape economic stagnation and poverty? In an attempt to answer such challenging but relevant questions, one part of the literature has focused on the relation between the health (life expectancy) and wealth (income per capita) of nations. This literature is typically motivated by a strong positive cross-country correlation between health and wealth, the so-called Preston curve (Preston, 1975); that is, healthier nations are also wealthier nations.

This paper continues this line of inquiry. Indeed, a seemingly important mechanism between health and wealth is the human capital channel: healthier people who live longer have stronger incentives to obtain education (Bloom and Canning, 2000). However, in a study of the behavior of American men born between 1840 and 1970, Hazan (2009) seriously questions the relevance of that mechanism. Hazan (2011) substantiates this view further by studying cross-country data in which he, for the latter part of the 20th century, finds no correlation between life expectancy at age 5 and schooling. Instead of only studying the cross-country OLS correlation over time, this paper aims at establishing whether health has a causal effect on schooling. Therefore, in the current paper the principal objective is to answer the following question:

- Do health improvements have a positive effect on schooling at the country level?

In answering this question, I rely on an empirical identification strategy proposed by Acemoglu and Johnson (2007), henceforth denoted AJ (2007). They argue that medical breakthroughs in the period 1940-1980 are by and large exogenous because the breakthroughs were not indigenously developed for most countries in the world. The authors use this fact to develop a predicted mortality instrument, which they use to identify the effect of health on wealth. In the current study, I utilize that same instrument to unveil the effect on years of schooling instead.

The empirical analysis reveals that health improvements have a positive effect on

years of schooling. In fact, the elasticity of schooling with respect to life expectancy at 
birth is estimated at 3.5. Furthermore, using life expectancy at age 20 shows that this result is not driven by reductions in infant or child mortality.

In general, this finding contributes to the literature by adding to the debate of whether health improvements influence the human capital channel positively and, in contrast to Hazan (2011), this paper provides evidence indicating that they do that. This result also suggests that the adverse effect of health on wealth recovered in AJ (2007) is not driven by the human capital channel, but rather by other channels such as the population channel. In addition, the finding of a positive link from life expectancy to schooling contributes to the theoretical literature which argues that this relation may be important in understanding the process of economic development (see, among others, Cervellati and Sunde, 2005; Soares, 2005; Ludwig and Vogel, 2010; Galor, 2011a).

An assessment of other empirical studies on the subject shows mixed evidence of how health and schooling are related at the national level. On the one hand, some studies have demonstrated a significant positive correlation (see, for example, Zhang and Zhang, 2005; Tamura, 2006; Murphy et al., 2008). However, those OLS correlations provide only suggestive evidence. The paper here contributes by establishing a positive link running from health to schooling and hereby supports the general conclusions made in that research. On the other hand, the study by Lorentzen et al. (2008) - which, for one thing, exploits exogenous geographical variables to identify the causal effect of adult mortality on secondary school enrollment rates - finds that mortality has no statistically significant effect on enrollment rates. This result tends to downplay the human capital channel as factor in the understanding of how life expectancy affects development. Nevertheless, by relying on an alternative identification strategy, as suggested by AJ (2007), and exploiting the panel data structure to eliminate country fixed effects, the study here arrives at the opposite conclusion: the human capital channel is in fact important in understanding how health improvements affect economic development.

This work also relates to the study by Cervellati and Sunde (2011). The authors argue that the effect of life expectancy on income per capita is nonmonotonic, and demonstrate - by dividing the countries in the AJ (2007) sample according to their 
stage of demographic transition - that life expectancy after the onset of the demographic transition has a positive effect on wealth. Similarly, in Cervellati and Sunde (2009), they argue that relationship between life expectancy and schooling follows the same pattern. In this paper, however, I present evidence suggesting that health has a positive effect on years of schooling for the complete sample of countries in AJ (2007). ${ }^{1}$

The paper is structured as follows. In Section 2, the hypothesis and empirical approach are outlined. In Section 3, the empirical evidence is presented. In Section 4, I place my result in the general health to wealth debate. In the final section, concluding remarks are offered.

\section{The hypothesis and empirical approach}

Economic theory suggests that increasing life expectancy induces individuals to obtain more schooling if it has a positive influence on the returns to schooling (or lowers the cost of it). One way in which the returns to schooling may be influenced is by a longer expected working life - the so-called horizon effect or Ben-Porath mechanism (BenPorath, 1967) — the idea being that the benefit from education is reaped over a longer period of time as the working horizon increases due to improvements in life expectancy. ${ }^{2}$ Another way is that longer lives may be associated with healthier and more productive lives, which potentially also increases the returns to schooling. ${ }^{3}$ Furthermore, positive general equilibrium effects of changes in population health may also raise the benefits and lower the cost of acquiring education, for example through higher wages. In sum,

\footnotetext{
${ }^{1}$ For a comprehensive overview of economic theories about the demographic transition see Galor (2011a; 2011b).

${ }^{2}$ The study by Hazan (2009) questions this theoretical argument. However, Hazan's conclusion has been criticized by Cervellati and Sunde (2010). Moreover, Hansen and Lønstrup (2011) argue that the empirical observations made in Hazan (2009) are consistent with the horizon effect.

${ }^{3}$ See Hazan and Zoabi (2006) for a theoretical model which incorporate this argument. Also, Bleakly (2007) presents empirical evidence for this effect from eradication of hookworm disease in the American South.
} 
these theoretical arguments seem to support the hypothesis that health improvements should have a causal positive effect on human capital accumulation.

Preliminary empirical evidence also provides support in favor of the hypothesis. Indeed, in Figure 1 and 2 countries are arranged according to their demographic development, as classified in Reher (2004). The first group of countries (group 1) is characterized by having experienced the onset of the demographic transition in 1940, whereas this is not so for the second group (group 2). From the figures it is evident that life expectancy as well as years of schooling have converged between the two groups. This finding suggests that health might have a causal effect on schooling. The rest of this paper is devoted to testing this hypothesis formally. ${ }^{4}$

Figure 1: Life expetancy at birth

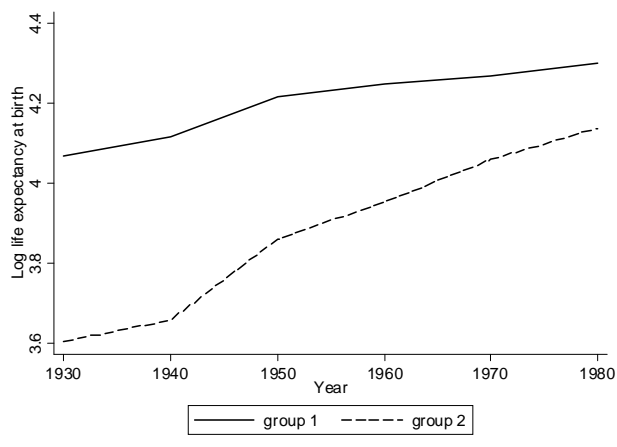

Notes: Group 1 (2) is characterized by an onsetting demographic transition before (after) 1940. Data sources: Reher (2004), AJ (2007) and Baier et al. (2006).

I assume that the effect of health on schooling and, thus, the accumulation of human capital, are described in a reduced-form manner by the following isoelastic relationship:

$$
S_{i t}=\delta_{i} X_{i t}^{\sigma}
$$

where $S_{i t}$ is average years of schooling for country $i$ in period $t, \delta_{i}$ is time invariant country specific effects, $X$ is life expectancy (health), and the parameter to be estimated

\footnotetext{
${ }^{4}$ Notice, this is also the classification employed in Cervellati and Sunde (2011), and if alternative classification standards are used, for example based on initial wealth, a similar pattern emerges.
} 
Figure 2: Average years of schooling

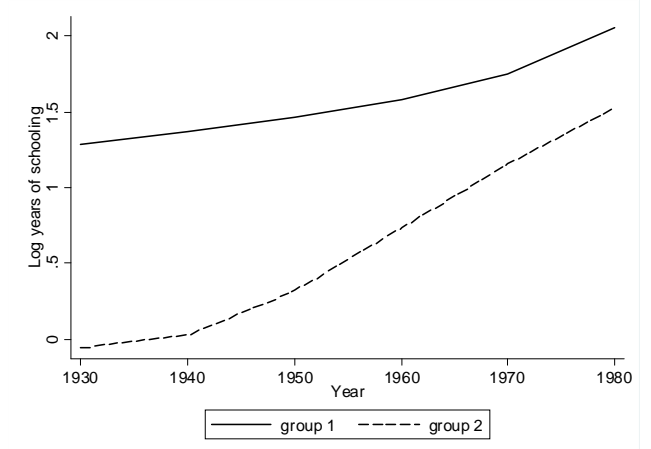

Notes: Group 1 (2) is characterized by an onsetting demographic transition before (after) 1940. Data sources: Reher (2004), AJ (2007) and Baier et al. (2006).

is $\sigma$. The reduced form specification in (1) is intended to capture the all-in-one influence of life expectancy on schooling, as mentioned above. Therefore, $\sigma$ should be interpreted as a net effect of national health improvements on years of schooling.

By adding time effects, $\mu$, and an error term, $\nu$, to equation (1), the basic estimation equation takes the following form:

$$
\log S_{i t}=\sigma \log X_{i t}+\delta_{i}+\mu_{t}+\nu_{i t}
$$

Even though $\delta_{i}$ and $\mu_{t}$ can easily be removed from the error term by fixed effect estimation and inclusion of time dummies, the naive OLS estimate of $\sigma$ is at best suggestive due to reversed causality and time varying omitted variables. To circumvent this issue, I follow the identification strategy employed in AJ (2007) by using their predicted mortality variable as an instrument for life expectancy. Again, notice that the hypothesis under investigation is whether $\sigma>0$.

I estimate $\sigma$ using a panel which consists of observations at 10-year intervals for the period 1940-1980, with data from from AJ (2007) and Baier et al. (2006). ${ }^{5}$

\footnotetext{
${ }^{5}$ I obtain similar results when estimating a long-difference model between 1940 and 1980 as in AJ (2007).

For the definitions, sources of variables and descriptive statistics see Table 1a and 2a in Appendix
} A. 


\section{Estimation results}

The first two columns of Table 1 report the estimates when the dependent variable is average years of schooling in the workforce. Column (1) shows a positive relation between schooling and health. On the face of it, the estimated magnitude implies that a 1 percent increase in life expectancy at birth is associated with 1.8 percent increase in years of schooling. The corresponding IV point estimate, reported in column (2), is 3.5 which in magnitude is significantly larger than the OLS estimate, suggesting that measurement error in health, creating attenuation bias, is possibly important. Nonetheless, this evidence here reveals that health, as measured by life expectancy at birth, has a positive impact on years of schooling.

Table 1: Life expectancy and human capital

\begin{tabular}{|c|c|c|c|c|}
\hline & \multicolumn{2}{|c|}{ log schooling } & \multicolumn{2}{|c|}{ log human capital } \\
\hline & OLS & IV & OLS & IV \\
\hline & (1) & $(2)$ & (3) & (4) \\
\hline $\begin{array}{l}\text { log life expectancy } \\
\text { at birth: }\end{array}$ & $\begin{array}{c}1.81^{* * *} \\
(0.38)\end{array}$ & $\begin{array}{c}3.53^{* * *} \\
(1.22)\end{array}$ & $\begin{array}{c}0.30 * * * \\
(0.07)\end{array}$ & $\begin{array}{c}0.60 * * * \\
(0.22)\end{array}$ \\
\hline 1-stage F-stat & - & 26.13 & - & 26.13 \\
\hline$R^{2}$ & 0.76 & 0.71 & 0.90 & 0.86 \\
\hline No. of countries & 47 & 47 & 47 & 47 \\
\hline
\end{tabular}

In columns (3) and (4) of Table 1, I consider the effect of health on an additional human capital measure, also taken from Baier et al. (2006). Basically, this measure is constructed on the basis of years of schooling and work experience. While the effect of health decreases in magnitude, the coefficient remains positive and statistically significant. Therefore, the evidence reveals that a 1 percent increase in life expectancy raises human capital per worker by 0.6 percent (see column 4$){ }^{6}$

\footnotetext{
${ }^{6}$ It is possible that the lower magnitude of health is a consequence of a negative relation between
} 
Hazan (2011) argues that the relation between life expectancy at age 5 and schooling is unstable over time, which possibly indicates that the results in Table 1 are driven by reductions in infant or child mortality. To investigate this matter further, Table 2 replaces life expectancy at birth with life expectancy at age 20 . This reduces the sample by 10 countries due to data limitations. Nevertheless, the evidence shows that life expectancy at age 20 has a positive effect on years of schooling. For example, the estimated coefficient in column (2) implies that a 1 percent increase in life expectancy at age 20 increases schooling by 5.8 percent.

Finally, cross-country schooling data from Morrisson and Murtin (2009) reveal that my results are robust to the choice of dependent variable. In particular, using average years of primary (secondary) schooling among the population older than 15 as dependent variable, I obtain an elasticity with respect to life expectancy at birth equal to 1.7 (4.5), an effect that is statistically significant at the 1 percent level.

In sum, this section has provided evidence that health, proxied by life expectancy, is causally and positively related to the accumulation of human capital skills, and it has also demonstrated that this result is not driven by gains in life expectancy in the early years of childhood.

life expectancy and working experience, which is also found in Hazan (2009). However, as is evident from Table 1, the effect on schooling more than compensates for this. 
Table 2: Adult life expectancy and human capital

\begin{tabular}{cccccc}
\hline \hline & \multicolumn{2}{c}{$\log$ schooling } & & \multicolumn{2}{c}{ log human capital } \\
\hline \hline & OLS & IV & & OLS & IV \\
\cline { 2 - 3 } \cline { 5 - 6 } & $(1)$ & $(2)$ & & $(3)$ & $(4)$ \\
\hline
\end{tabular}

$\log$ life expectancy

at age 20

$2.89^{*} \quad 5.77^{* * *} \quad 0.50^{*} \quad 1.07^{* *}$

$(1.50) \quad(2.01) \quad(0.24)$

$\begin{array}{lllll}\text { 1-stage F-stat } & - & 20.6 & - & 20.6\end{array}$

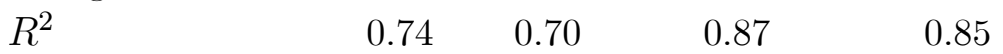

\begin{tabular}{llllc} 
No. of countries & 37 & 37 & 37 & 37 \\
\hline Notes: Clustering robust standard errors in parentheses. ${ }^{* * *}{ }_{\mathrm{p}}<_{0.01, * *}{ }_{\mathrm{p}}<0.05,{ }^{*}{ }_{\mathrm{p}}<_{0.1}$. All
\end{tabular}

regressions are estimated by within group estimation and include a full set of time fixed effects.

\section{Health and wealth}

In this section, I discuss how the empirical evidence presented so far fits in the debate of how health affects wealth and economic development.

Start by assuming that the economic wide production function is described by:

$$
Y_{i t}=K_{i t}^{\alpha}\left(A_{i t} H_{i t}\right)^{1-\alpha}
$$

where $0<\alpha<1, Y$ is total output, $K$ is the aggregate capital stock, $A$ is total factor productivity, and $H_{i t}=h_{i t} N_{i t}$ is the total human capital stock, where $h$ is human capital per working person and $N$ is the total working population. In addition, assume the following reduced-form relations:

$$
\begin{aligned}
K_{i t} & =\bar{K}_{i} X_{i t}^{\phi} \\
A_{i t} & =\bar{A}_{i} X_{i t}^{\gamma} \\
h_{i t} & =\bar{h}_{i} X_{i t}^{\eta} .
\end{aligned}
$$

Now, by substituting (4) into (3), taking logs and adding an error term, $\epsilon_{i t}$, I obtain the following expression:

$$
\ln \tilde{y}_{i t}=\pi \log X_{i t}+\mathbb{C}_{i}+\epsilon_{i t}
$$


where $\pi \equiv \alpha \phi+(1-\alpha)(\gamma+\eta), \tilde{y}$ is output per worker, and $\mathbb{C}_{i}$ captures the country specific effects from (4).

Using data on output per worker from Baier et al. (2006) together with the same empirical strategy as followed in the last section, I obtain an IV estimate of $\pi=-0.76$, which is statistically significant at the 5 percent level. Also, using the same data source, I find $\phi=-1.68$ and $\gamma=-0.54$, both statistically significant at the 10 percent level. Finally, the influence on human capital is already estimated in column (4) of Table $1, \eta=0.60$. All in all, the evidence suggests that health has a negative effect on wealth (output per worker). ${ }^{7}$ However, it is also evident that the negative effect is not operating through the human capital channel.

The empirical evidence put forward in AJ (2007) indirectly suggests that $\gamma+\eta$ is negative or close to zero because health improvements have a negative influence on wealth (income per capita). The evidence here suggests that $\eta>0$ but $\gamma<0$. Still, the combined effect is close to zero as found by AJ (2007). ${ }^{8}$

Finally, the fact that health improvements seem to have an adverse effect on income also suggests that the positive effect on schooling, uncovered in the previous section, is not caused by a pure income effect.

\section{Concluding remarks}

This paper has provided evidence for the relevance and importance of the human capital channel: healthier nations with longer lived populations also spend more time on schooling and hereby acquire better human capital skills.

\footnotetext{
${ }^{7}$ I have also estimated the effect on output per capita with data from Baier et al. (2006), and here the negative health effect is even larger in magnitude (-1.40).

${ }^{8}$ In the working paper by Acemoglu and Johnson (Acemoglu and Johnson, 2006), the authors find no effect of health improvements on schooling; however, their study lacks schooling data from 1940 to 1960. The current investigation has data for the complete period from Baier et al. (2006) and Morrisson and Murtin (2009).
} 
Using the same empirical strategy as AJ (2007) to identify the effect of life expectancy on human capital, I find that a 1 percent increase in life expectancy at birth (age 20) increases years of schooling by 3.5 (5.8) percent.

This evidence challenges the results obtained by Hazan (2011), who questions the quantitative importance of the human capital channel, and the evidence confirms the traditional idea that health improvements have a universal positive influence on the accumulation of human capital.

Finally, this paper confirms the main result obtained in AJ (2007) that, if anything, life expectancy has an adverse effect on wealth. However, the evidence put forward here emphasizes that this result is not drifting through the human capital channel. On the contrary, the human capital seems to alleviate the negative influence from other possible channels, such as total factor productivity or capital accumulation. This result also shows that the positive effect on schooling is not governed by general improvements in living standards. 


\section{Appendix A}

Table 1a: Description of variables and data sources

\begin{tabular}{lll}
\hline \hline Abbre- & Description: & Source: \\
viation: & & \\
& & \\
\hline$S_{1}$ & years of schooling in the workforce, age 15-64 & Baier et al. (2006) \\
$S_{2}$ & years of primary schooling in the population, age 15+ & Morrisson and Murtin (2009) \\
$S_{3}$ & years of secondary schooling in the population, age 15+ + & Morrisson and Murtin (2009) \\
$X_{b i r t h}$ & life expectancy at birth & AJ (2007) \\
$X_{20}$ & life expectancy at age 20 & AJ (2007) \\
$h$ & human capital per worker & Baier et al. (2006) \\
$i i$ & predicted mortality (instrument) & AJ (2007) \\
$\tilde{y}$ & income per worker & Baier et al. (2006) \\
$y$ & income per capita & Baier et al. (2006) \\
$k$ & physical capital per worker & Baier et al. (2006) \\
$A$ & total factor productivity & Baier et al. (2006) \\
\hline
\end{tabular}


Table 2a: Descriptive statistics

\begin{tabular}{|c|c|c|c|c|c|}
\hline Variable: & \# obs. & mean & std. dev. & $\min$ & $\max$ \\
\hline$X_{b i r t h}$ & 235 & 59.57 & 12.11 & 29.9 & 75.86 \\
\hline$X_{20}$ & 170 & 70.18 & 5.18 & 51.66 & 77.17 \\
\hline$S_{1}$ & 217 & 4.01 & 2.28 & 0.23 & 11.64 \\
\hline$S_{2}$ & 200 & 3.98 & 1.63 & 0.67 & 6.01 \\
\hline$S_{3}$ & 200 & 1.50 & 1.32 & 0.01 & 5.29 \\
\hline$i i$ & 235 & 0.15 & 0.21 & 0 & 0.97 \\
\hline $\log h$ & 217 & 0.22 & 0.22 & -0.24 & 0.66 \\
\hline $\log \tilde{y}$ & 217 & 8.94 & 0.86 & 6.60 & 10.41 \\
\hline $\log y$ & 220 & 7.91 & 0.93 & 5.45 & 9.64 \\
\hline $\log k$ & 217 & 9.24 & 1.00 & 7.06 & 11.21 \\
\hline $\log A$ & 220 & 5.02 & 0.44 & 3.42 & 5.93 \\
\hline
\end{tabular}




\section{References}

[1] Acemoglu, D., Johnson, S., 2006. Disease and Development: The Effect of Life Expectancy on Economic Growth. Working paper, 12269, NBER, Cambridge, MA.

[2] Acemoglu, D., Johnson, S., 2007. Disease and Development: The effect of life expectancy on economic growth. Journal of Political Economy, 115(6), 925-985.

[3] Baier, S. L., Gerald, P., Dwyer, JR., Tamura, R., 2006. How Important are Capital and Total Factor Productivity for Economic Growth? Economic Inquiry, 44(1), 2349.

[4] Ben-Porath, Y., 1967. The Production of Human Capital and the Life Cycle of Earnings. Journal of Political Economy, 75, 352-365.

[5] Bleakly, H., 2007. Disease and Development: Evidence from Hookworm Eradication in the American South. Quarterly Journal of Economics, 122(1), 73-117.

[6] Bloom, D., Canning, D., 2000. The Health and Wealth of Nations. Science, 18(287), 1207-1209.

[7] Cervellati, M., Sunde, U., 2005. Human Capital, Life Expectancy, and the Process of Development. American Economic Review, 95(5), 1653-1672.

[8] Cervellati, M., Sunde, U., 2009. Life Expectancy and Economic Growth: The Role of the Demographic Transition. IZA discussion paper, 4160.

[9] Cervellati, M., Sunde, U., 2010. Longevity and Lifetime Labor Supply: Evidence and Implications Revisited. Working paper.

[10] Cervellati, M., Sunde, U., 2011. Life Expectancy and Economic Growth: The Role of the Demographic Transition. Journal of Economic Growth, 16(2), 99-133.

[11] Galor, O., 2011a. Unified Growth Theory. Princeton University Press. 
[12] Galor, O., 2011b. The Demographic Transition: Causes and Consequences. Cliometrica, (in press).

[13] Hansen, C., Lønstrup, L., 2011. Can higher life expectancy induce more schooling and earlier retirement? Journal of Population Economics, (in press).

[14] Hazan, M., Zoabi, H., 2006. Does Longevity Cause Growth? A Theoretical Critique. Journal of Economic Growth, 11, 363-376.

[15] Hazan, M., 2009. Longevity and Lifetime Labor Supply: Evidence and Implications. Econometrica, 77, 1829-1863.

[16] Hazan, M., 2011. Life Expectancy and Schooling: New Insights from Cross-Country Data. Journal of Population Economics, (in press).

[17] Lorentzen, P., McMillan, J., Wacziarg, R., 2008. Death and Development. Journal of Economic Growth, 13(2), 81-124.

[18] Ludwig, A., Vogel, E., 2010. Mortality, Fertility, Education and Capital Accumulation in a simple OLG Economy. Journal of Population Economics, 23, 703-735.

[19] Morrisson, C., Murtin, F., 2009. The Century of Education. Journal of Human Capital, 3(1), 1-42.

[20] Murphy, K.M., Simon, C., Tamura, R., 2008. Fertility Decline, Baby Boom and Economic Growth. Journal of Human Capital, 2(3), 262-300.

[21] Preston, S. H., 1975. The changing relation between mortality and level of economic development. Population Studies, 29(2), 231-248.

[22] Reher, D.S., 2004. The demographic transition revisited as a global process. Population Space and Place, 10(1), 19-41.

[23] Soares, R. R., 2005. Mortality Reductions, Educational Attainment, and Fertility Choice. American Economic Review, 95(3), 580-601. 
[24] Tamura, R., 2006. Human capital and economic development. Journal of Development Economics, 79, 26-72.

[25] Zhang, J., Zhang J., 2005. The Effect of Life Expectancy on Fertility, Saving, Schooling and Economic Growth: Theory and Evidence. Scandinavian Journal of Economics, 107(1), 45-66. 